\title{
Uma história da psiquiatria mexicana a partir das fontes clínicas do Manicomio La Castañeda
}

\author{
A history of Mexican psychiatry based on clinical \\ sources from the La Castañeda insane asylum
}

\author{
Giulia Engel Accorsi ${ }^{i}$ \\ ' Doutoranda, Programa de Pós-graduação em História das Ciências e da Saúde/Fiocruz. \\ orcid.org/0000-0001-7178-7830 \\ gengelaccorsi@gmail.com
}

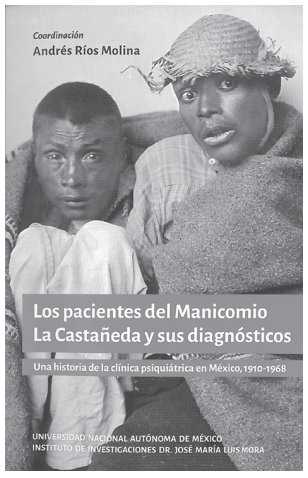

RÍOS MOLINA, Andrés (Coord.). Los pacientes del Manicomio La Castañeda y sus diagnósticos: una historia de la clínica psiquiátrica en México, 1910-1968. Ciudad de México: Universidad Nacional Autónoma de México/Instituto de Investigaciones Históricas; Instituto de Investigaciones Dr. José María Luis Mora. 2017. $452 p$.

Los pacientes del Manicomio La Castañeda y sus diagnósticos: una historia de la clínica psiquiátrica en México, 1910-1968 (Ríos Molina, 2017) traz boas contribuições não somente para o campo dos estudos sobre a história da psiquiatria, mas para o conjunto de pesquisas que enfoca a trajetória dos pacientes psiquiátricos, os diagnósticos e as instituições asilares a partir da análise de documentos clínicos.

Fruto do trabalho coletivo de ampla rede de pesquisadores, a obra organizada por Andrés Ríos Molina, publicada em 2017, confirma a importância da concretização do longo e audacioso projeto de elaboração de uma base de dados que abriga mais de 12 mil registros pertencentes a indivíduos internados no Manicomio General de La Castañeda durante todo seu período de funcionamento (19101968). A cifra corresponde a apenas $20 \%$ de todos os documentos encontrados, por meio dos quais foi possível recuperar informações sobre aproximadamente 15 variáveis, entre elas sexo, idade, estado civil, profissão e diagnóstico.

Evidenciando a polifonia das fontes em questão, os oito textos que compõem a coletânea abordam o perfil de pacientes internados sob diagnósticos de esquizofrenia, retardo mental, paralisia geral progressiva, epilepsia, alcoolismo, toxicomania, entre outros. Os processos de enquadramento dos indivíduos nessas categorias de sofrimento mental são analisados a partir dos valores morais, socioculturais e das concepções científicas em voga durante os diferentes períodos analisados. Assim, as reflexões trazidas pelos autores vão ao encontro de questionamentos colocados por estudos como The confinement of the insane, obra editada por Roy Porter e David Wright, publicada em 2003.

Sem perder de vista a natureza disciplinadora que as instituições psiquiátricas trazem em sua essência, os artigos acerca do manicômio mexicano evidenciam a complexidade 
das relações de poder estabelecidas em um dos mais importantes espaços asilares desse país. Contribuindo para a desconstrução da ideia de que a medicina mental fazia uso indiscriminado de certas técnicas e medicamentos, os autores também criticam, em parte, a visão de que o hospício era um lugar de clausura eterna.

No texto em que relaciona a esquizofrenia, a demência precoce e a psicose maníacodepressiva, por exemplo, Molina desconstrói a ideia de que a assumida cronicidade dessas enfermidades culminava em um longo período de internação. Chamando atenção para as transformações no significado dos dois primeiros termos ao longo do tempo, o autor conclui que a implementação orientada do uso de antipsicóticos e do eletrochoque em La Castañeda coincidiu com a diminuição do tempo de enclausuramento dos doentes portadores de tais diagnósticos. José Antonio Maya Gonzáles também nota que, no caso da epilepsia, a diminuição do número de mortes e da média de tempo de internação por essa enfermidade durante o período de 1935-1968 coincide igualmente com o estabelecimento da terapêutica por meio de determinados psicofármacos.

Palco de uma série de transformações institucionais, teóricas e metodológicas no campo da medicina mental, o manicômio é caracterizado não somente como um espaço de experimentação, mas de ensino, formação médica e consolidação de campos de estudo independentes. Em seu Pavilhão Central, inaugurado em 1932, foram introduzidas novas tecnologias para o diagnóstico e tratamento das doenças mentais e gestada a primeira geração de psiquiatras mexicanos, amplamente influenciada pelas concepções da psiquiatria organicista alemã.

Em sua pesquisa sobre a paralisia geral progressiva (PGP), Alejandro Giraldo Granada evidencia tal influência, estabelecendo relações entre o processo de aceitação da etiologia sifilítica da PGP e a consolidação do campo psiquiátrico no México, ocorrida especialmente durante as décadas de 1920 e 1930. Já Daniel Vicenzio coteja os entendimentos médicos acerca dos diferentes tipos de transtornos neurológicos identificados em La Castañeda no curso da separação entre os campos da neurologia e da psiquiatria. Segundo o autor, tal emancipação foi marcada pela apropriação de técnicas diagnósticas, de tratamento e, especialmente, pela criação de instituições especializadas nas doenças que passaram a ser consideradas, então, objetos específicos da neurologia.

Alguns textos também trazem questionamentos a respeito das muitas apropriações possíveis do espaço manicomial - que vão para além das figuras do médico e do paciente -, destacando igualmente as influências do contexto histórico nos processos de estabelecimento de certos diagnósticos psiquiátricos em La Castañeda. Segundo Alejandro Salazar Bermúdez, o alcoolismo foi enquadrado de diferentes maneiras pelos psiquiatras ao longo de todo o funcionamento do manicômio, passando por um processo de medicalização em que parâmetros - especialmente morais - cederam lugar a referenciais então considerados científicos.

José Luis Pérez Gonzáles chega a conclusões similares no que diz respeito às toxicomanias, argumentando que as bases psiquiátricas para se diagnosticar um indivíduo como toxicômano eram muito amplas e ambíguas. Em seu artigo, que encerra a coletânea, o autor também mostra que a instituição mexicana foi considerada pelas famílias não apenas como um lugar onde o processo de desintoxicação seria possível, mas também como um 
espaço de represália pelo hábito, considerado nocivo, apresentado pelos indivíduos que abusavam de substâncias como a cocaína e a morfina.

As pesquisas apresentadas partem de análises bastante preliminares e ainda imaturas da documentação em questão, chegando a conclusões muito amplas e genéricas e prometendo estudos mais precisos adiante. No que diz respeito à metodologia, não ficam claros os referenciais que orientaram a decisão de analisar apenas 1/5 de todos os registros encontrados, o que seria fundamental para a proposta em questão, uma vez que se compromete com uma abordagem qualitativa, mas, sobretudo, quantitativa. Ainda assim, destaco as ricas reflexões que Los pacientes del Manicomio La Castañeda y sus diagnósticos traz para o campo da história da psiquiatria, inspirando projetos que visam resgatar as diferentes vozes que podem ser ouvidas por meio da análise de fontes clínicas.

\section{REFERÊNCIAS}

RÍOS MOLINA, Andrés (Coord.). Los pacientes del Manicomio La Castañeda y sus diagnósticos: una historia de la clínica psiquiátrica en México, 1910-1968. Ciudad de México: Universidad Nacional Autónoma de México/Instituto de Investigaciones Históricas; Instituto de Investigaciones Dr. José María Luis Mora. 452p. Disponível em: <www.historicas. unam.mx/publicaciones/publicadigital/ libros/687/pacientes_manicomio.html>. Acesso em: 17 mar. 2019. 2017.

PORTER, Roy; WRIGHT, David (Ed.). The confinement of the insane: international perspectives, 1800-1965. Cambridge: Cambridge University Press. 2003. 